\title{
HUBUNGAN PERNIKAHAN USIA DINI DENGAN GANGGUAN KEHAMILAN DI WILAYAH KERJA PUSKESMAS PIJORKOLING
}

\author{
Juliana Lubis ${ }^{1}$, Susi Febriani Yusuf ${ }^{2}$ \\ ${ }^{1,2}$ STIKes Darmais Padangsidimpuan, Padangsidimpuan, Indonesia

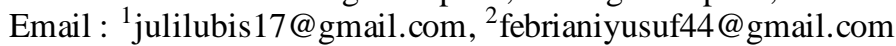

\begin{abstract}
ABSTRAK
Pernikahan yang di lakukan pada usia muda tersebut dilakukan di berbagai kategori pedesaan maupun diperkotaan dan menyebabkan perbedaan pendapat. Berdasarkan SDKI tahun 2007 berkaitan dengan pernikahan dibawah umur, di bermacam wilayah terhitung sepertiga dari total pernikahan yang terdata yaitu pasangan remaja di usia dibawah 16 tahun. Jawa timur merupakan daerah yang angka pernikahan usia remaja mencapai $39,40 \%$, kalimantan selatan $35,48 \%$ dan jawa barat $36 \%$. Adapun tujuan dari penelitian yang dilakukan adalah untuk mengetahui hubungan pernikahan di usia dini dengan gangguan kehamilan di wilayah kerja puskesmas pijorkoling.

Penelitian ini adalah penelitian yang bersifat analitik dengan desain case control, dengan data primer, dengan menggunakan lembar observasi. Populasi 31 ibu hamil dan pengambilan sampel dengan total sampling yaitu $31 \mathrm{ibu}$ hamil menikah di usia dini sebagai kasus dan 31 ibu hamil yang menikah normal sebagai kontrol dan di analisa dengan uji chi-square.

Hasil penelitianyang dilakukan menunjukkan bahwa ibu hamil yang ada gangguan kehamilan sebanyak 29 orang $(46,8 \%)$ dan ada hubungan pernikahan pada usia dini $\mathrm{P}=0.005(\alpha<0.05)$.

Kesimpulan yang didapatkandari penelitian ini adalah ada hubungan pernikahan usia dini dengan gangguan kehamilan. Disarankan kepada puskesmas agar memberikan penyuluhan kepada remaja tentang bahaya menikah di usia dini.
\end{abstract}

Kata kunci : Pernikahan Usia Dini, Gangguan Kehamilan

\section{ABSTRACT}

Marriages that are carried out at a young age are carried out in various categories of rural and urban areas and cause differences of opinion. Based on the 2007 IDHS relating to underage marriage, in various regions accounting for a third of the total marriages recorded were teenage couples under the age of 16 years. East Java is an area where the teenage marriage rate reaches $39.40 \%$, South Kalimantan 35.48\% and West Java 36\%. The purpose of this study was to determine the relationship between early marriage and pregnancy disorders in the working area of the Pijorkoling Public Health Center.

This study is an analytic study with a case control design, with primary data, using an observation sheet. Population 31 pregnant women and sampling with a total sampling of 31 pregnant women married at an early age as cases and 31 pregnant women who married normally as controls and analyzed by chi-square test.

The results of the study showed that 29 pregnant women (46.8\%) had pregnancy disorders and there was a relationship between marriage at an early age $P=0.005(\alpha<0.05)$.

The conclusion obtained from this study is that there is a relationship between early marriage and pregnancy disorders. Recommended to the puskesmas to provide counseling to adolescents about the dangers of getting married at an early age.

Keywords: Early Marriage, Pregnancy Disorders 


\section{Pendahuluan}

Masa remaja (10-19 tahun) merupakan masa peralihan dari masa kanak - kanak menuju usia lebih matang dimana terjadi perubahan secara fisik, mental (jiwa) juga psikososial yang cepat dan berdampak pada berbagai aspek kehidupan selanjutnya. (Sibagariang, 2010).

Pernikahan usia $<20$ dan $>35$ tahun ini akan berpengaruh pada kehamilannya kelak. Seorang ibu yang sudah hamil di umur 22-35 tahun disebabkan saat usia tersebut keadaan fisik ibu lebih baik dan terjadi puncak kesuburan. Ibu yang sedang hamil diusia lebih muda dan orang seksual dan reproduksinya belum mencapai tigkat kematangan yang seharusnya. Dengan demikian dapat menyebabkan berbagai resiko yaitu prematuritas pada bayi, keguguran dalam kehamilan, perdarahan post partum dan terjadinya gangguan pertumbuhan dan perkembangan pada janin. Resiko lainnya usia yang sangat muda dan usia yang masih labil dan mengalami permasalahan secara emosional saat kehamilan terjadi. (Raden, 2009)

Jumlah kasus pernikahan dini di Indonesia mencapai 50 juta jumlah penduduk, dengan perhitungan berkisar usia perkawinan 19,1 tahun. Bahkan, di sejumlah pedes aan, pernikahan sering kali dilakukan segera setelah anak perempuan mendapat haid pertama (Fadlyana \& Larasaty, 2016)

Diusia muda melakukan pernikahan baik di wilayah kota maupun desa dapat menyebabkan berbagai kontraversi. Berdasark an SDKI 2007 terkait dengan pernikahan usia muda, diberbagai daerah tercatat sepertiga dari jumlah pernikahan terdata dilakukan pas angan usia dibawah 16 tahun. Di Jawa timur, angka pernikahan dini mencapai 39,40\%, Kalimantan selatan 35,48\%, Jambi 30,63\% dan Jawa Barat 36\%(Fadlyana \& Larasaty, 2016)

Menurut penelitian Yulisah 2011, ada hubungan pernikahan di usia dini dengan gangguan kehamilan. Dimana adanya hubungan menikah usia dini dengan kejadian abortus sebanyak 52,3\% dan adanya hubungan menikah usia dini dengan anemia kehamilan sebanyak $59,5 \%$. Sehingga pernikahan usia dini ada hubungan yang signifikan dengan kejadian abortus/keguguran dan anemia kehamilan (RINA, Batubara, \& Hasanah, 2019).

Saat kehamilan pada usia dibawah umur dapat menyebabkan berbagai resiko secara medis yang cukup mengkhawatirkan, karena usia ini secara reproduksi belum saatnya berfungsi semestinya. Kesiapan uterus melakukang fungsi secara baik saat setelah umur si ibu 20 tahun, disebabkan fungsi secara hormonal maksimal. Umur 15-19 tahun hormonal belum bekerja stabil. Sis tem hormonal yang tidak stabil maka akan menyebabkan kehamilan kurang stabil, anemia, perdarahan, kematian janin atau lahir sebelum waktunya.(Kusmiran, 2012).

Faktor penyebab timbulnya pernikahan usia dini dikalangan remaja yaitu sebab dari anak : faktor pendidikan, faktor telah melakukan hubungan biologis, hamil sebelum menikah. Dan sebab diluar anak yaitu kurangnya nilai agama, kemiskinan/ekonomi dan kebiasaan atau budaya (Ikhsanudin \& Nurjanah, 2018). 
Berdasarkan survey awal pendahuluan yang dilalui penulis di wilayah kerja puskesmas piorkoling, jumlah pasangan yang sudah menikah yang menikah 312 . Jumlah pas angan yang menikah saat usia dini 182 orang. Penelitian ini bertujuan untuk mengetahui Hubungan Pernikahan Usia Dini Dengan Gangguan Kehamilan Di Wilayah Kerja Puskes mas Pijorkoling.

\section{Metode Penelitian}

Jenis penelitian adalah salah satu bentuk rancangan penelitian analitik dengan metode observasional menggunakan desain case control. Populasi dan sampel dalam penelitian ini yaitu $31 \mathrm{ibu}$ hamil dimana usia kehamilan trimester II.

\section{Hasil dan Pembahasan}

\section{Hubungan Pernikahn Usia Dini dengan Gangguan Kehamilan di Wilayah Kerja Puskesmas Pijorkoling}

Tabel 1 Hubungan Pernikahn Usia Dini dengan Gangguan Kehamilan di Wilayah Kerja Puskesmas Pijorkoling

\begin{tabular}{|c|c|c|c|c|c|c|c|}
\hline \multirow{3}{*}{$\begin{array}{c}\text { Pernikahan } \\
\text { dini }\end{array}$} & \multicolumn{4}{|c|}{ Gangguan kehamilan } & \multirow{2}{*}{\multicolumn{2}{|c|}{ Total }} & \multirow[t]{3}{*}{ Prob } \\
\hline & \multicolumn{2}{|c|}{$\begin{array}{c}\text { Ada } \\
\text { gangguan }\end{array}$} & \multicolumn{2}{|c|}{$\begin{array}{l}\text { Tidak ada } \\
\text { gangguan }\end{array}$} & & & \\
\hline & $n$ & $\%$ & $n$ & $\%$ & $\mathbf{n}$ & $\%$ & \\
\hline$<20$ tahun & 20 & 64,5 & 11 & 35,5 & 31 & 100 & $\mathrm{P}=0.005$ \\
\hline$>20$ tahun & 9 & 29,0 & 22 & 70,9 & 31 & 100 & $\mathrm{OR}=4.444$ \\
\hline Total & 29 & 46,8 & 33 & 53,2 & 62 & 100 & \\
\hline
\end{tabular}

Berdasarkan tabel 4.5 dapat lihat bahwa ibu hamil yang pernikahan dini kurang dari 20 tahun ibu hamil yang mengalami ada gangguan kehamilan sebanyak 20 orang $(64,5 \%)$ dan ibu hamil yang tidak adagangguan kehamilan yaitu 11 orang $(35,5 \%)$. Sedangkan ibu hamil yang pernikahan normal $>20$ tahun, ibu hamil yang ada gangguan sebanyak 9 orang $(29,0 \%)$ dan ibu hamil yang tidak ada gangguan s 22 orang $(70,9 \%)$. Berdasarkan uji statistik di peroleh nilai $\mathrm{p}=0,005(\alpha<0,05)$ dan $\mathrm{OR}=4.444$ dengan hasil ada hubungan yang erat pernihan dini dengan gangguan kehamilan.

Menurut asumsi peneliti yang membandingkan pernikahn dini sabgai kasus dan pernikahan normal sebagai kontrol. Menikah usia dini tinggi mengalami gangguan kehamilan dibanding dengan menikah saat usia normal. Pada masa remaja sangatlah menjadi masa yang sangat dikhawatirkan karena kesiapan organ reproduksi yang belum matang yang menimbulkan komplikasi saat kehamilan dan melahirkan di sebabkan umur ibu muda, keadaan mental dan phisikologis berpengaruh terhadap kesiapan remaja dalam menjalani pernikahan yang masih dini, kesiapan untuk menjalankan masa kehamilan sangat dikhawatirkan remaja dengan menikah diusia dini. 


\section{Kesimpulan}

Gangguan kehamilan ibu yang menikah ada 29 orang (46,8\%) yang mengalami gangguan kehamilan, usia $<20$ tahun diperoleh 20 orang yang mengalami gangguan kehamilan $(64,5 \%)$ yaitu gangguan anemia kehamilan dan keguguran. Ada hubungan pernikahan dini dengan gangguan kehamilan, dengan nilai $p=0,005(\alpha<0.005)$.

\section{Daftar Pustaka}

Fadlyana, E., \& Larasaty, S. (2016). Pernikahan usia dini dan permasalahannya. Sari Pediatri, 11(2), 136-141.

Ikhsanudin, M., \& Nurjanah, S. (2018). Dampak Pernikahan Dini Terhadap Pendidikan Anak Dalam keluarga. Al-I'tibar: Jurnal Pendidikan Islam, 5(1), 38-44.

Kusmiran, E. (2012). Kesehatan Repsroduksi Remaja Dan WanitaJakarta. Selatan: Salemba Medika.

Raden, J. N. (2009). Hubungan antara kejadian abortus dengan usia ibu hamil di RSUD Dr. Moewardi Surakarta pada tahun 2008.

RINA, K., Batubara, S., \& Hasanah, N. (2019). PERAN PENYULUH AGAMA ISLAM

DALAM MENCEGAH PERNIKAHAN DINI DI KECAMATAN KUMPEH KABUPATEN MUARO JAMBI. UIN Sulthan Thaha Saifuddin Jambi.

Sibagariang, E. E. (2010). Kesehatan reproduksi wanita. 